University of Wollongong

Research Online

Faculty of Business - Papers (Archive)

Faculty of Business and Law

$1-1-2014$

Convergence in sovereign debt ratios across heavily indebted EU countries: evidence from club convergence

N Apergis

University of Piraeus

Arusha Cooray

University of Wollongong, arusha@uow.edu.au

Follow this and additional works at: https://ro.uow.edu.au/buspapers

Part of the Business Commons

Research Online is the open access institutional repository for the University of Wollongong. For further information contact the UOW Library: research-pubs@uow.edu.au 


\title{
Convergence in sovereign debt ratios across heavily indebted EU countries: evidence from club convergence
}

\author{
Abstract \\ We study the convergence of sovereign debt accumulation in five European Monetary Union (EMU) \\ countries using quarterly data from June 2009 to June 2013, with a focus on debt ratio convergence \\ following the 2009 sovereign debt crisis and the adoption of fiscal consolidation programmes. We test \\ the Phillips and Sul (2007) club convergence hypothesis. We find the evidence of a lack of debt \\ convergence for Greece and Portugal. Our results support the view that there is not a uniform austerity \\ prescription for all, especially, without emphasizing friendly growth policies, which makes these countries \\ more prone to investors' sentiments.
}

\section{Keywords}

sovereign, evidence, countries, eu, club, indebted, convergence, heavily, across, ratios, debt

\section{Disciplines \\ Business}

\section{Publication Details}

Apergis, N. \& Cooray, A. (2014). Convergence in sovereign debt ratios across heavily indebted EU countries: evidence from club convergence. Applied Economics Letters, 21 (11), 786-788. 


\title{
Convergence in sovereign debt ratios across highly in debt EU countries: evidence from club convergence
}

\begin{abstract}
We study the convergence of sovereign debt accumulation in 5 EMU countries using quarterly data from 2009 to 2012 with a focus on debt ratios convergence following the 2009 sovereign debt crisis and the adoption of fiscal consolidation programs. We test the Phillips and Sul (2007) club convergence hypothesis. We find evidence of a lack of debt convergence for Greece and Portugal. Our results support the view that there is not a uniform austerity prescription for all, especially, without emphasizing friendly growth policies, which makes these countries more prone to investors' sentiments.
\end{abstract}

Keywords: debt ratios, convergence, club convergence approach, countries under fiscal consolidation

JEL Classification: H62, H63, C33 


\section{Introduction}

In the eye of the sovereign debt storm provoked by the 2008-10 world crisis as well as the failure of some European Monetary Union (EMU) member countries, specifically, Cyprus, Greece, Ireland, Italy, Portugal, and Spain, to comply with the requirement of a Debt/GDP ratio of less than 60 percent of GDP has led to the introduction of a number of austerity measures (i.e., fiscal consolidation), including public expenditure cuts and higher taxes. These economies are currently caught up in a vicious cycle of austerity measures making recovery more difficult. Critics argue that these measures are counter-productive, pushing the countries further into recession. Given that these countries faced different initial conditions and debt dynamic paths, implying that they should have adopted different policies (the wellknown issue of 'one size doesn't fit all'), the fact of receiving homogeneous austerity measures could have jeopardized the success of such programs and the speedy exit from the crisis.

At the same time, these countries' interdependence implies that the debt motion law of one country depends on that of the others; thus, in the presence of spillovers across them policy actions should take them into account. Moreover, fiscal convergence is an important pre-requisite for the efficient functioning of the EMU, the goal of this paper is to explore debt convergence (potentially to a debt target ratio) in these countries after the recent debt sovereign crises in the EMU. Concerns that fiscal policy might jeopardize the stability of the debt target and the currency have been paramount (Galor, 1996). That rationale is well documented in the literature (Artis and Winkler 1997; Beetsma 2001; Fatas et al., 2003). The results will shed light on the long-term evolution of debt/GDP ratios, growth rates and longterm interest rates in these countries after a period of strict fiscal consolidation programs. Our paper's novelties are twofold. It analyzes debt ration convergence after the recent crisis on debt in a group of countries that adopted fiscal consolidation programs, while the implementation of the new methodology of panel convergence testing, recommended by Phillips and Sul (2007) based on the club convergence hypothesis, which considers that certain countries that belong to a club move from disequilibrium positions to their clubspecific steady-state positions. This methodology has several appealing characteristics: i) no specific assumptions concerning the stationarity of the variable of interest are necessary, ii) this convergence test is interpreted as an asymptotic cointegration test without suffering from the small sample problems, and iii) it is based on a quite general form of a nonlinear time varying factor model. 
Although debt sustainability has been the focus of many theoretical and empirical papers (Escolano, 2010), few have specifically considered debt ratios convergence, while Gros (2011) shows that austerity policies could be self-defeating.

The paper is organized as follows: Section 2 discusses the methodological framework, while Section 3 analyzes convergence issues on debt dynamics through econometric estimations. Section 4 concludes.

\section{Methodology}

In this section, we outline the methodology proposed by Phillips and Sul (2007) (henceforth PS) to test for convergence in a panel of countries and to identify any convergence clubs. PS propose an econometric approach for testing the convergence hypothesis and the identification of convergence clubs. Their method uses a nonlinear time-varying factor model and provides the framework for modeling transitional dynamics as well as long run behavior. Furthermore, their statistical methodology can test for convergence in economic variables other than output. The new methodology adopts the following time-varying common-factor representation for $y_{i t}$ of country i:

$y_{i t}=\delta_{i t} \mu_{t}$

where $\mu_{t}$ is a single common component and $\delta_{i t}$ is a time-varying idiosyncratic element that captures the deviation of country $i$ from the common path defined by $\mu_{t}$. Within this framework, all $\mathrm{N}$ economies will converge, at some point in the future, to the steady state, if $\lim _{k \rightarrow \infty} \delta_{i t+k}=\delta$ for all $\mathrm{i}=1,2, \ldots, \mathrm{N}$, irrespective of whether countries are near the steady state or in transition. This is important given that the paths to the steady state (or states) across countries can differ significantly.

The goal of PS is to test whether variables $y_{i t}, i=1,2, \ldots, N$ tend to converge to a single steady state as $t \rightarrow \infty$. To this direction they adopt a factor representation $y_{i t}=\delta_{i t} \mu_{t}$ for each variable in the sample. The factor $\mu_{t}$ is assumed common across economies, while the transition dynamics are captured by the idiosyncratic components $\delta_{i t}$ which are allowed to vary across cross section and time. Convergence is a dynamic process. Since $\delta_{i t}$ trace out the transition paths, convergence can be tested by examining the temporal relative evolution of 
$\delta_{i t}$. PS do not assume any parametric form for $\mu_{t}$; they just factor it out and they concentrate on $\delta_{i t}$. Since we cannot directly estimate $\delta_{i t}$ from equation (1) due to overparameterization, PS assume a semiparametric form for $\delta_{i t}$, which enables them to construct a formal test for convergence. In particular, they eliminate the common component $\mu_{t}$ through rescaling by the panel average:

$$
h_{i t}=\frac{y_{i t}}{\frac{1}{N} \sum_{i=1}^{N} y_{i t}}=\frac{\delta_{i t}}{\frac{1}{N} \sum_{i=1}^{N} \delta_{i t}} .
$$

The relative measure $h_{i t}$ captures the transition path with respect to the panel average. Defining a formal econometric test of convergence as well as an empirical algorithm of defining club convergence requires the following assumption for the semi-parametric form for the time-varying coefficients $\delta_{i t}$ :

$\delta_{i t}=\delta_{i}+\sigma_{i t} \xi_{i t}$

where $\sigma_{i t}=\frac{\sigma_{i}}{L(t) t^{\alpha}}, \sigma_{i}>0, t \geq 0$, and $\xi_{i t}$ is weakly dependent over t, but iid(0,1) over i. The function $L(t)$ varies slowly, increasing and diverging at infinity. Under this specific form for $\delta_{i t}$, the null hypothesis of convergence for all $\mathrm{i}$, takes the form: $H_{0}: \delta_{i}=\delta, \quad \alpha \geq 0$, while the alternative hypothesis of non-convergence for some i, takes the form: $H_{A}: \quad \delta_{i} \neq \delta$ or $\alpha<0$. PS show that we can test for the null of convergence in the framework of the following regression:

$$
\log \left(\frac{H_{1}}{H_{t}}\right)-2 \log L(t)=\hat{c}+\hat{b} \log t+\hat{u}_{t}
$$

for $t=[r T],[r T]+1, \ldots . ., T$, and $r>0 . .^{1}$ In this regression, $H_{t}=\frac{1}{N} \sum_{i=1}^{N}\left(h_{i t}-1\right)^{2}$ and $\hat{b}=2 \hat{\alpha}$, where $h_{i t}$ is defined in equation (2) and $\hat{\alpha}$ is the least squares estimate of $\alpha$. Under the null hypothesis of convergence, the dependent variable diverges whether $\alpha>0$, or $\alpha=0$. In this case, we can test the convergence hypothesis by a $t$-test of the inequality, $\alpha \geq 0$. The $t$-test

\footnotetext{
${ }^{1}$ Following the recommendation of PS, we choose $r$ values in the interval $[0.2,0.3]$.
} 
statistic follows the standard normal distribution asymptotically and is constructed using a heteroskedasticity and autocorrelation consistent standard error. PS call the one-sided $t$-test, which is based on $t_{\hat{b}}$, the $\log t$ test due to the presence of the log $t$ regressor in equation (4).

\section{Empirical analysis}

Quarterly data on net sovereign debt to GDP ratios are obtained from the Datastream database for Cyprus, Greece, Ireland, Portugal, and Spain spanning the period 2009-2012.

Table 1 reports the empirical results. The results of the full sample reject the null hypothesis of debt convergence, since the point estimate of the $\log (t)$ statistic is -13.928 (with critical value equal to -1.67). The results indicate the presence of two clubs. Three countries (Cyprus, Ireland, and Spain) form the first club, whereas the second club includes the remaining two countries (Greece and Portugal). The 2 different clubs indicate that although all countries adopted fiscal consolidation programs, the two groups followed different routes, indicating that the implementation of a uniform consolidation program cannot achieve the same (expected) results if it ignores the idiosyncratic characteristics of each country.

Table 1: Debt ratios convergence

\begin{tabular}{|c|c|c|c|}
\hline & Countries & $\begin{array}{c}\text { b } \\
\text { coefficient }\end{array}$ & t-stat \\
\hline \multirow{2}{*}{ Full sample } & Cyprus, Greece, Ireland, Italy, Portugal, Spain & & \\
\hline & & -0.794 & -13.928 \\
\hline $\mathbf{1}^{\text {st }}$ club & Cyprus, Ireland, Italy, Spain & -0.374 & -1.092 \\
\hline \multirow{2}{*}{$\mathbf{2}^{\text {nd }}$ club } & Greece, Portugal & 1.563 & 3.875 \\
\hline
\end{tabular}

Phillips and Sul (2009) argue that the convergence club methodology overestimates the number of clubs than their true number. To avoid this overdetermination, they estimate 
convergence across the sub-clubs to assess whether any evidence exists in support of merging clubs into larger clubs. The results are reported in Table 2. The empirical findings display that for the two sub-clubs there is no evidence to support mergers of the original clubs.

Table 2: Convergence club classification

Club Tests of club merging

1

Club $1+2=-0.116^{*}$

$(-5.93)$

2

* denotes statistical significant at the $5 \%$ level and rejects the null hypothesis of convergence. The figures in parenthesis denote t-statistics.

\section{Conclusions}

This paper offered an empirical analysis of debt ratios convergence for a number of EMU countries that have been explicitly or implicitly under fiscal consolidation programs followed the 2009 sovereign debt crisis. It examined debt ratios convergence for Cyprus, Greece, Ireland, Italy, Portugal, and Spain, countries that implement austerity programs following the debt sovereign crisis of 2009. The results documented that although Cyprus, Ireland and Spain continued to be in the same convergence club, while Greece and Portugal formed their own club, potentially indicating that fiscal consolidation programs in these countries did not have the expected results, implying the slow response of the debt ratio to fiscal adjustment. Although the reasons for their failure are beyond the scope of this paper, the results suggest that a uniform fiscal consolidation program might be insufficient to establish debt convergence in troubled countries.

This raises high concerns in terms of financial market funding of continuing fiscal deficits, unless, as Cottarelli and Jaramillo (2012) highlight, the composition of fiscal adjustment can be rebalanced to make it more 'growth friendly'. A relief may only come from growth. Our results should be interpreted with caution. In particular, they do not imply that fiscal consolidation is undesirable or could place public debt on an unsustainable path. 


\section{References}

Artis, M., Winkler, B., 1997. The stability pact: Safeguarding the credibility of the European Central Bank. National Institute Economic Review, January, 87-98.

Beetsma, R., 2001. Does EMU need a stability pact? In: Brunila, A., Buti, M., Franco, D., (Eds.), The Stability and Growth Pact, Palgrave, 23-52.

Chow, G.C., Lin, A. 1971. Best linear unbiased interpolation, distribution, and extrapolation of time series by related series. The Review of Economics and Statistics 53, 372-375.

Cottarelli, C., Jaramillo, L. 2012. Walking hand-in-hand: fiscal policy and growth in advanced economies. IMF Working Paper 12/137, Washington: International Monetary Fund.

Escolano, J. 2010. A practical guide to public debt dynamics, fiscal sustainability, and cyclical adjustment of budgetary aggregates. IMF Technical Notes and Manuals 10/02, Washington: International Monetary Fund.

Fatas, A., Hughes Hallett, A., von Hagen, J., Sibert, A., Strauch, R., 2004. Stability and growth in Europe: Towards a better pact. Centre for Economic Policy Research, London.

Galor, O. 1996. Convergence? Inferences from theoretical models, Economic Journal 106, 1056-1069.

Gros, D. 2011. Can austerity be self-defeating?, Economic Policy, CEPS Commentaries.

Phillips P.C.B., Sul D. 2009. Economic transition and growth. Journal of Applied Econometrics 24, 1153-1185.

Phillips, P.C.B., Sul, D. 2007. Transition modeling and econometric convergence tests. Econometrica 75, 1771-1855. 